\title{
Intraperitoneal administration of tumor-targeting Salmonella typhimurium A1-R inhibits disseminated human ovarian cancer and extends survival in nude mice
}

\author{
Yasunori Matsumoto ${ }^{1,2,3, *}$, Shinji Miwa ${ }^{1,2,4, *}$, Yong Zhang ${ }^{1}$, Ming Zhao ${ }^{1}$, Shuya \\ Yano $^{1,2}$, Fuminari Uehara ${ }^{1,2}$, Mako Yamamoto ${ }^{1,2}$, Yukihiko Hiroshima ${ }^{1,2}$, Makoto \\ Toneri $^{1,2}$, Michael Bouvet ${ }^{2}$, Hisahiro Matsubara ${ }^{3}$, Hiroyuki Tsuchiya ${ }^{4}$ and Robert M. \\ Hoffman $^{1,2}$ \\ ${ }^{1}$ AntiCancer, Inc, San Diego, CA, USA \\ 2 Department of Surgery, University of California San Diego, San Diego, CA, USA \\ ${ }^{3}$ Department of Frontier Surgery, Graduate School of Medicine, Chiba University, Chiba, Japan \\ ${ }^{4}$ Department of Orthopaedic Surgery, Graduate School of Medical Sciences, Kanazawa University, Ishikawa, Japan \\ * These authors contributed equally to this work \\ Correspondence to: Robert M. Hoffman, email: all@anticancer.com \\ Ming Zhao, email: all@anticancer.com
}

Keywords: ovarian cancer, orthotopic, mouse model, bacterial therapy, Salmonella typhimurium A1-R

Received: February 06, $2015 \quad$ Accepted: February 21, 2015

Published: March 16, 2015

This is an open-access article distributed under the terms of the Creative Commons Attribution License, which permits unrestricted use, distribution, and reproduction in any medium, provided the original author and source are credited.

\section{ABSTRACT}

Peritoneal disseminated cancer is highly treatment resistant. We here report the efficacy of intraperitoneal (i.p.) administration of tumor-targeting Salmonella typhimurium A1-R in a nude mouse model of disseminated human ovarian cancer. The mouse model was established by intraperitoneal injection of the human ovarian cancer cell line SKOV3-GFP. Seven days after implantation, mice were treated with S. typhimurium A1-R via intravenous (i.v.) or i.p. administration at the same dose, $5 \times 10^{7} \mathrm{CFU}$, once per week. Both i.v. and i.p. treatments effected prolonged survival compared with the untreated control group $(P=0.025$ and $P<0.001$, respectively). However, i.p. treatment was less toxic than i.v. treatment. Tumor-specific targeting of $S$. typhimurium A1-R was confirmed with bacterial culture from tumors and various organs and tumor or organ colony formation after i.v. or i.p. injection. Selective tumor targeting was most effective with i.p. administration. The results of the present study show S. typhimurium A1-R has promising clinical potential for disseminated ovarian cancer, especially via i.p. administration.

\section{INTRODUCTION}

Ovarian cancer is a leading cause of cancer-related death among women in the U.S. with 22,000 being diagnosed and 14,000 deaths each year [1]. If the cancer has distantly spread from the ovary, the 5-year survival rate is $27 \%[2,3]$ since platinum-based chemotherapy, which is first-line, for ovarian cancer with peritoneal dissemination [4], has low efficacy.

For more than 200 years cancers have been observed to regress following acute bacterial infections, mostly streptococcal [5]. In the late 19th and early 20th centuries. Coley infected cancer patients with Streptococcus pyrogenes and later treated the patients with extracts of the bacteria, which became known as Coley's toxins. Coley often had very good results with both the bacteria and the toxins [6].

Recently, there has been intense interest to develop bacterial therapy of cancer [6,7]. The barriers in tumors for standard therapy such as hypoxia, acidic $\mathrm{pH}$, disorganized vascular architecture, are beneficial for bacteria to target cancer [7].

One approach to bacterial therapy of cancer is to use anaerobic bacteria such as Bifidobacterium [8] and Clostridium [9] which replicate in necrotic areas of tumors. Anaerobic bacteria cannot grow in oxic viable 
tumor tissue, which restricts their efficacy. In addition, obligate anaerobic bacteria may be limited to intratumor (i.t.) injection which would preclude their use for metastatic cancer.

Recently a human patient with metastatic leiomyosarcoma was treated by i.t. injection of Clostridium novyi (C. novyi)-NT spores which reduced the tumor within and surrounding the bone [10].

Salmonella typhimurium, which is a facultative anaerobe, was previously attenuated with purine and other auxotrophic mutations, as well as lipid A-modified (msbB), and termed VNP20009 [11], VNP20009 was tested in a Phase I clinical trial on patients with metastatic melanoma and renal cell carcinoma [12].

Another strain of S. typhimurium, A1-R, has been developed by our laboratory and has increased antitumor efficacy compared to VNP20009 [13]. S. typhimurium A1-R is auxotrophic for Leu-Arg which prevents it from mounting a continuous infection in normal tissues. A1-R has no other attenuating mutations as does VNP20009 and, therefore, has higher tumor virulence. A1-R was able to eradicate primary and metastatic tumors in monotherapy in nude mouse models of prostate, breast, lung and pancreatic cancer, as well as sarcoma and glioma [1422]. Tumors with a high degree of vascularity were more sensitive to A1-R, and vascular destruction appears to play a role in A1-R antitumor efficacy $[23,24]$.

S. typhimurium A1-R can target chemo-resistant pancreatic cancer stem-like cells [25] and pancreatic cancer patient-derived PDOX orthotopic xenographs [26].

In a recent study, we demonstrate that A1-R inhibits tumor growth, dissemination, and metastasis and extends survival in mouse models of aggressive human ovarian cancer [27].

The present study demonstrates $S$. typhimurium A1-R is highly effective for disseminated ovarian cancer, especially when administered i.p.

\section{RESULTS AND DISCUSSION}

\section{S. typhimurium A1-R inhibits ovarian cancer cell proliferation in vitro in a dose-dependent manner}

S. typhimurium A1-R was effective on SKOV3-GFP ovarian cancer cells in vitro. The number of SKOV3-GFP colonies was $649.3 \pm 39.6$ in the control group; $597.3 \pm$ 30.4 when treated with $1 \times 10^{7} \mathrm{CFU} / \mathrm{ml}$ S. typhimurium A1-R; $396.7 \pm 25.0$ when treated with $1 \times 10^{8} \mathrm{CFU} / \mathrm{ml}$ S. typhimurium A1-R; and $247.0 \pm 12.7$ when treated with $1 \times 10^{9} \mathrm{CFU} / \mathrm{ml}$ of $S$. typhimurium A1-R (Fig. 1a,b). SKOV3-GFP colony areas were $30.5 \pm 2.9(\%$ of dish area) in control group; $14.1 \pm 0.8(\%$ of dish area $)$ when treated with $1 \times 10^{7} \mathrm{CFU} / \mathrm{ml}$ of $S$. typhimurium A1-R; 7.17 $\pm 0.5\left(\%\right.$ of dish area) when treated with $1 \times 10^{8} \mathrm{CFU} / \mathrm{ml}$ of $S$. typhimurium A1-R; and $2.30 \pm 0.9(\%$ of dish area $)$ when treated with $1 \times 10^{9} \mathrm{CFU} / \mathrm{ml}$ of $S$. typhimurium A1-R (Fig. 1c). These results indicate that $S$. typhimurium A1-R inhibits proliferation of SKOV3-GFP cells in a dosedependent manner.

\section{Establishment of the nude-mouse model of human ovarian cancer peritoneal dissemination}

Two weeks after i.p. implantation of SKOV3-GFP cells $\left(5 \times 10^{6}\right)$, tumor dissemination was confirmed in all 10 mice on the peritoneum visualized with GFP imaging (Fig. 2 ). Tumors were confirmed at sacrifice and laparotomy. Disseminated tumors growing in the abdominal cavity led to animal death at approximately 40 days (Fig. 2).

\section{S. typhimurium A1-R therapy extended the survival period of the peritoneal dissemination model}

Nude mice with disseminated ovarian cancer were divided into three groups: untreated control; treatment with i.v. injection of $S$. typhimurium A1-R $\left(5 \times 10^{7} \mathrm{CFU}\right)$; and treatment with i.p. injection of $S$. typhimurium A1-R $\left(5 \times 10^{7} \mathrm{CFU}\right)$. Median survival in the control group was 35 days; i.v. -treated group, 47 days; and i.p.-treated group 60 days. One mouse in the i.v.-treated group and three mice in the i.p.-treated group survived to day 90. Treatment with i.v. or i.p. injection of $S$. typhimurium A1-R significantly prolonged the survival period compared with the control group ( $p=0.025$ and $p<0.001$, respectively, Fig. $3 \mathrm{c}, \mathrm{d})$.

The body weight was compared among the three groups to assess the toxicity of bacterial therapy. Maximum body weight loss was $8.8 \%$ in the i.v. group on day 1 , and $5.8 \%$ in the i.p group on day 2 . The body weight recovered by day 5 in the i.p. group. These results indicate that i.p. bacterial therapy is more effective for disseminated ovarian cancer and less toxic than i.v. injection.

\section{S. typhimurium A1-R administrated i.p. is eliminated from normal tissues}

Ten nude mice without tumor were also treated by i.v. or i.p. injection of $S$. typhimurium A1-R (Fig. 4a). Twenty-four hours after bacterial injection, blood, ascites, liver, spleen and tumor were harvested from each mouse and seeded on LB-Agar dishes. After 24-hour culture, $S$. typhimurium A1-R colony formation was assessed with fluorescence imaging (OV100, Olympus, Japan) (Fig. $4 \mathrm{~b}, \mathrm{c})$. In mice without tumors, no $S$. typhimurium A1-R was detected when treated i.p.. In contrast, spleens in two mice treated with i.v. injection of $S$. typhimurium A1-R had colony formation. In mice with disseminated ovarian 
a
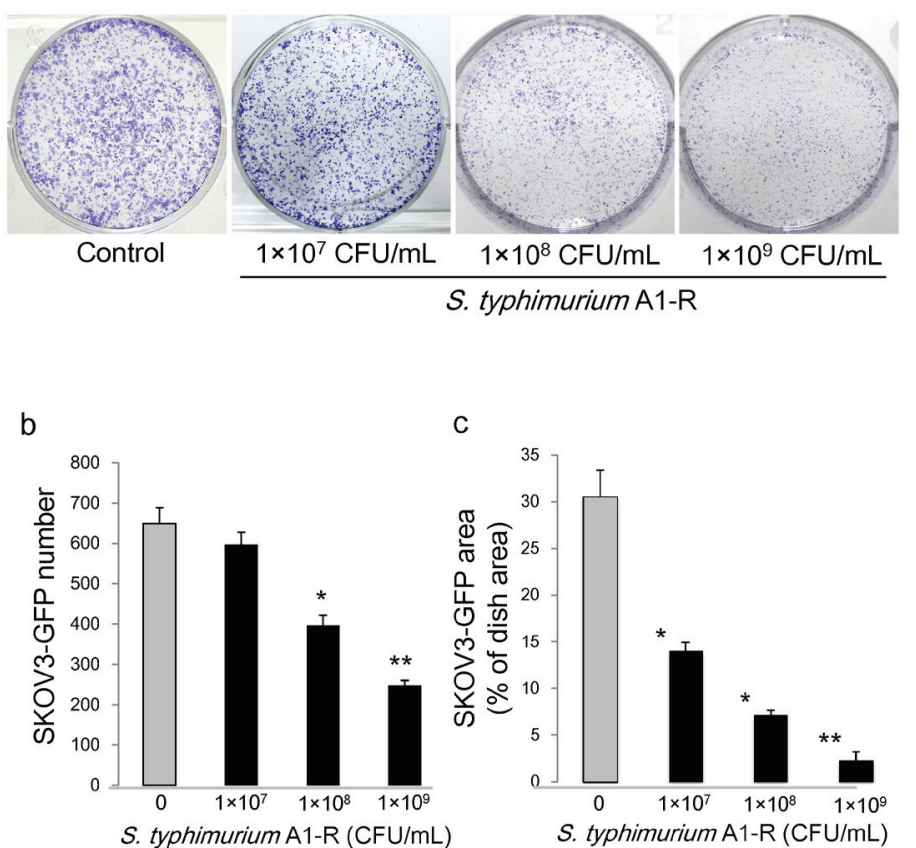

Figure 1: Efficacy of S.typhimurium A1-R on ovarian cancer cells in vitro. a. Clonogenic assays were performed. b. SKOV3GFP colony number after $S$. typhimurium A1-R treatment. c. SKOV3-GFP colony area after $S$. typhimurium A1-R treatment. $* \mathrm{P}<0.05$, ${ }^{* *} \mathrm{P}$ $<0.01$ compared with the control group.

a

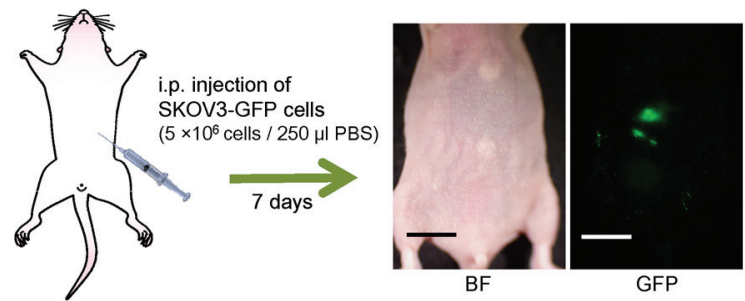

b

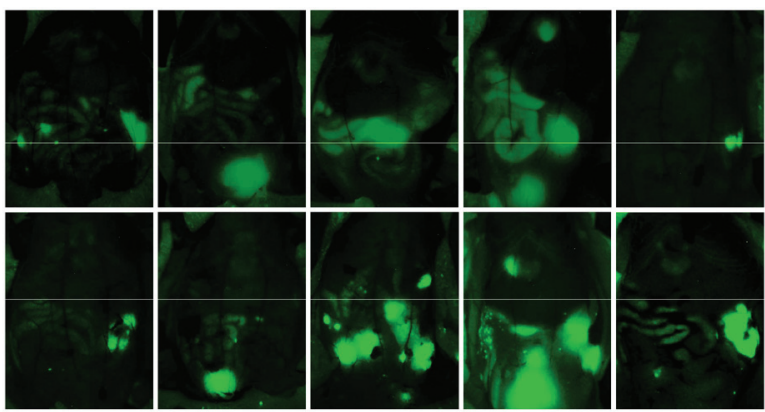

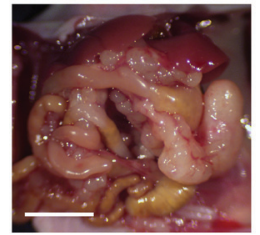

$\mathrm{BF}$

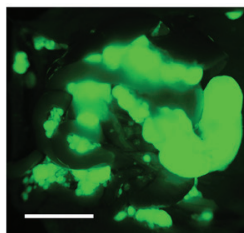

GFP

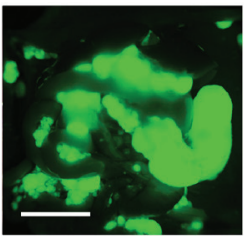

$\mathrm{BF}+\mathrm{GFP}$

Figure 2: Nude mouse model of disseminated ovarian cancer. a. Within seven days after i.p. injection of SKOV3-GFP cells $\left(5 \times 10^{6}\right.$ cells in $\left.250 \mu \mathrm{PBS}\right)$, disseminated tumors appeared, visualized by fluorescence imaging (Bar: $\left.1 \mathrm{~cm}\right)$. b. Fluorescence imaging via the peritoneum on day 14. c. Representative intraperitoneal imaging at death. (Bar: $1 \mathrm{~cm}$ ) BF: bright field. 
a

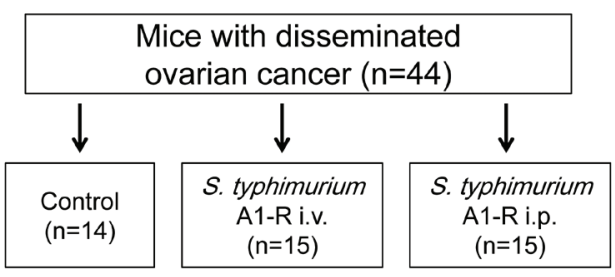

b

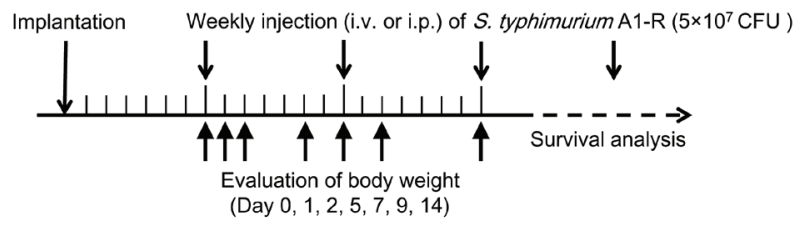

C

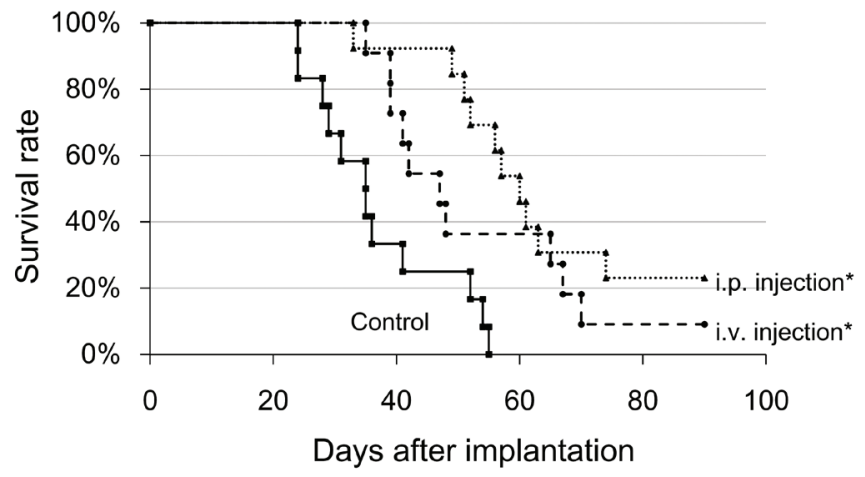

d

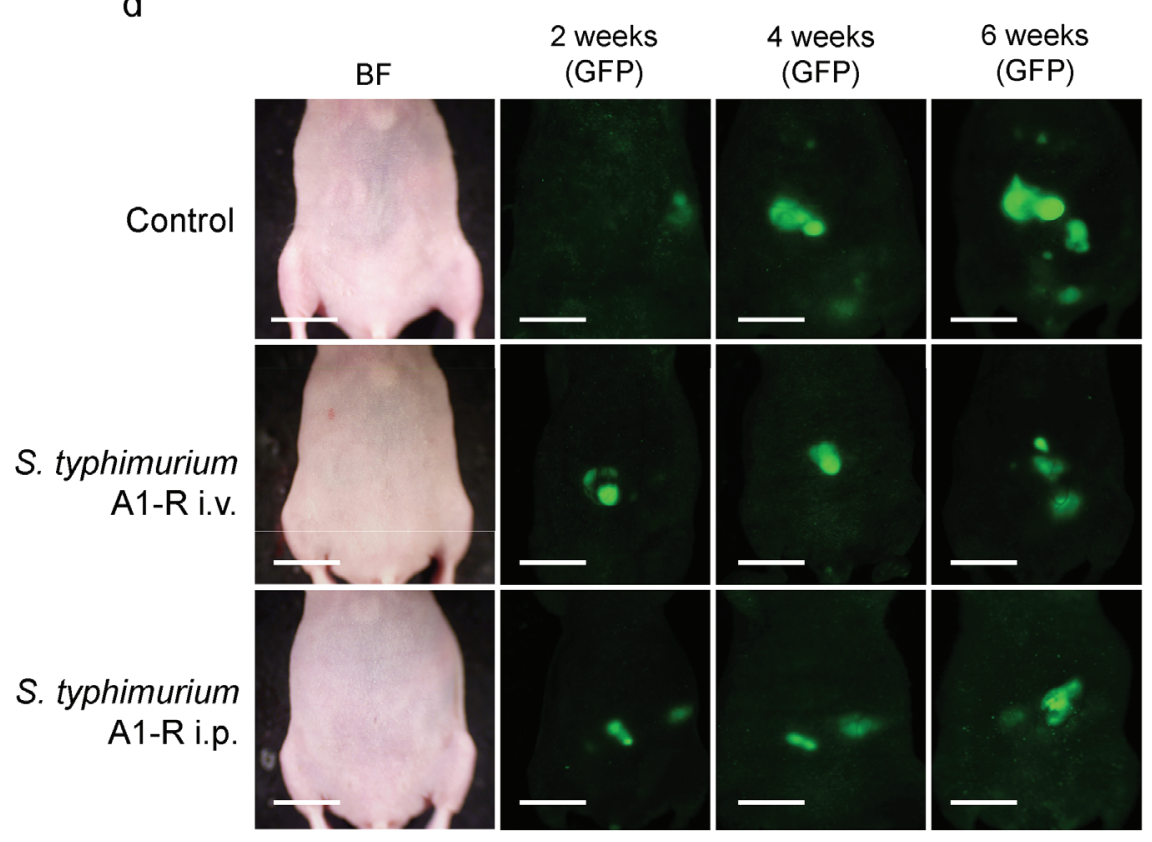

Figure 3: $S$. typhimurium A1-R treatment of disseminated ovarian cancer. a. Study design for comparing the route of administration of S. typhimurium A1-R. b. Treatment schedule. On day 0, SKOV3-GFP cells were $\left(5 \times 10^{6}\right)$ injected into the peritoneal cavity in 45 nude mice. On day 7, tumor formation was confirmed in 44 mice. Mice were divided into three groups. S. typhimurium A1-R ( $\left.5 \times 10^{7} \mathrm{CFU}\right)$ was injected i.v. or i.p. once a week starting from day 7. To assess the toxicity of A1-R treatment, the body weight of all mice was measured on days $0,1,2,5,7,9,14$. c. Survival curves of treated and control groups of mice. The survival period of the treated mice was significantly prolonged compared with the untreated control group $(\mathrm{P}=0.025$ in i.v. group; $\mathrm{P}<0.001$ in i.p. group). d. Representative time-course images of treated and control mice (bright-field $[\mathrm{BF}]$ and GFP imaging, Bar: $1 \mathrm{~cm}$ ). 
cancer, i.p. injection resulted in higher amounts of $S$. typhimurium A1-R in the tumors. In contrast, i.v. injection of $S$. typhimurium resulted in bacterial colonies grown from blood, liver, and spleen as well as tumor (Table 1). This result indicates that $S$. typhimurium A1-R can be eliminated from tissues in mice without tumors and $S$. typhimurium A1-R administrated i.p. had greater tumor specificity then when administered i.v.

Our results demonstrate that i.p. administration of $S$. typhimurium A1-R has higher antitumor efficacy and less toxicity in nude mouse models of disseminated ovarian cancer, demonstrating clinical potential for this currently highly treatment-resistant disease.

The tumor-targeting of disseminated ovarian cancer strategy developed in the present report could also be used with previously-developed tumor targeting strategies [2835]. a

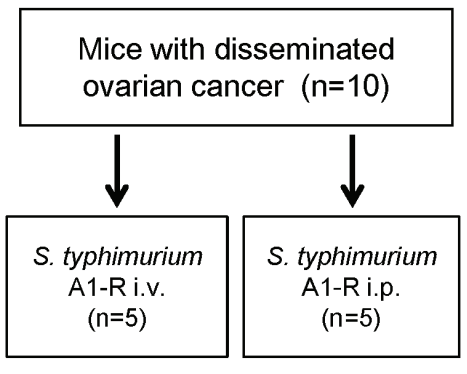

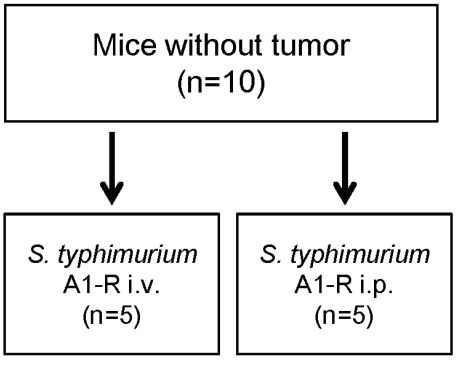

b

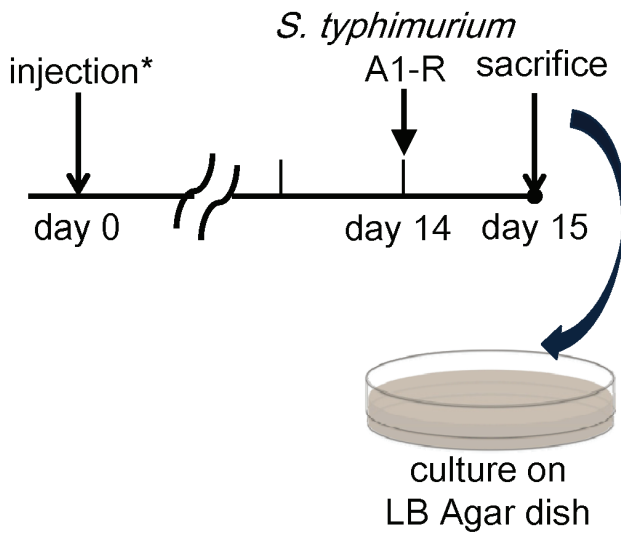

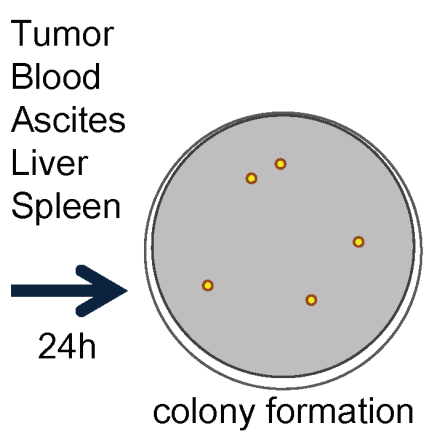

S. typhimurium A1-R positive

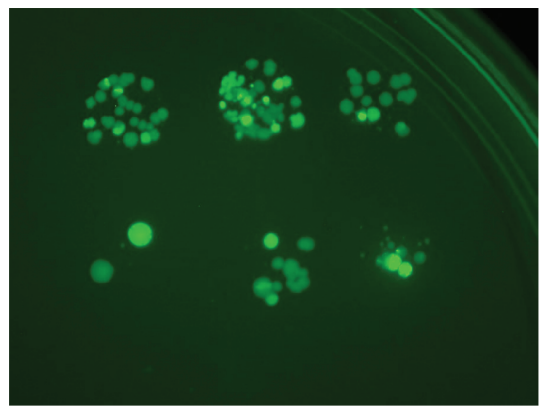

Figure 4: Selective tumor-targeting of $\boldsymbol{S}$. typhimurium A1-R after different routes of treatment. a. Study design. Twenty mice were divided into two groups: injection of SKOV3-GFP cells $\left(5 \times 10^{6}\right.$ cells $)$ or PBS into the peritoneal cavity. Half of the mice in each group were treated with i.v. or i.p. injection of S. typhimurium A1-R. b. Schedule of the study. Fourteen days after injection, S. typhimurium A1-R $\left(5 \times 10^{7} \mathrm{CFU}\right)$ were injected i.v. or i.p. into each of five mice with or without tumor. Twenty-four hours after treatment, all mice were sacrificed. Blood, ascites, liver, spleen, and tumors were harvested for culture of S. typhimurium A1-R. Each tissue was seeded on LB-Agar medium with serial dilution in triplicate. Colony formation was assessed after 24 hours with fluorescence imaging (OV-100). c. Representative negative and positive findings of $S$. typhimurium A1-R colony formation. 
Table 1: S. typhimurium A1-R colony formation on LB agar

\begin{tabular}{|c|c|c|c|c|}
\hline \multirow{2}{*}{} & \multicolumn{2}{|c|}{ Tumor (-) } & \multicolumn{2}{c|}{ Tumor (+) } \\
\cline { 2 - 5 } & ip & iv & ip & iv \\
\hline Tumor & N/A & N/A & $5 / 5$ & $3 / 5$ \\
\hline Blood & $0 / 5$ & $0 / 5$ & $0 / 5$ & $1 / 5$ \\
\hline Ascites & $0 / 5$ & $0 / 5$ & $2 / 5$ & $0 / 5$ \\
\hline Liver & $0 / 5$ & $0 / 5$ & $1 / 5$ & $5 / 5$ \\
\hline Spleen & $0 / 5$ & $2 / 5$ & $2 / 5$ & $4 / 5$ \\
\hline
\end{tabular}

N/A: Not available

\section{MATERIALS AND METHODS}

\section{Cell line and culture conditions}

The SKOV3-GFP [36] human ovarian cancer cell line (AntiCancer, Inc., San Diego, CA) was used for this study. Cells were maintained in Dulbecco's modified Eagle's medium supplemented with $10 \%$ fetal bovine serum (Sigma-Aldrich). All media were supplemented with penicillin and streptomycin (Gibco-BRL). Cells were cultured at $37^{\circ} \mathrm{C}$ with $95 \%$ air and $5 \% \mathrm{CO}_{2}$.

Mice

Athymic nude mice (nu/nu) (AntiCancer, Inc.), 7 weeks, were used. Mice were kept in a barrier facility under HEPA filtration. Mice were fed with autoclaved laboratory rodent diet. All animal studies were conducted in accordance with the principles and procedures outlined in the NIH guide for the Care and Use of Laboratory Animals under assurance number A3873-1.

\section{Preparation of S. typhimurium A1-R for treatment}

GFP-expressing S. typhimurium A1-R bacteria (AntiCancer Inc., San Diego, CA, USA) were grown overnight in LB medium and then diluted 1:10 in LB medium. Bacteria were harvested at late-log phase, washed with PBS, and then diluted in PBS. Bacteria were then ready for injection in mice [16].

\section{Clonogenic assay}

SKOV3-GFP cells were grown in 6-well plates to a density of approximately $1 \times 10^{3}$ cells/well. S. typhimurium A1-R GFP were diluted in cell culture medium and added to the cancer cells at either $1 \times 10^{7}, 1 \times 10^{8}$ or $1 \times 10^{9} \mathrm{CFU} / \mathrm{ml}$ and incubated for $60 \mathrm{~min}$ at $37^{\circ} \mathrm{C}$. The cells were rinsed and cultured in medium containing gentamycin sulfate $(20 \mu \mathrm{g} / \mathrm{ml})$ to kill external, but not internal, bacteria. After seven days culture, cancer-cell colonies were fixed with ethanol and then stained with crystal violet. The number of colonies and the ratio of colony areas were assessed by ImageJ (National Institutes of Health, Bethesda, MD).

\section{Dissemination model of ovarian cancer in nude mice}

To establish a mouse model of ovarian cancer dissemination in the peritoneal cavity, SKOV3-GFP cells $\left(5 \times 10^{6}\right)$ suspended in $250 \mu \mathrm{l}$ PBS were injected into the peritoneal cavity in nude mice. Two weeks after implantation, tumor formation were assessed with fluorescence imaging and laparotomy. The Olympus OV100 Small Animal Imaging System (Olympus, Tokyo, Japan) was used for whole body imaging in live mice [37].

\section{S. typhimurium A1-R therapy of disseminated ovarian cancer in nude mice}

Seven days after the implantation of SKOV3-GFP cells as described above, intra-abdominal tumor formation was confirmed with fluorescence imaging in 44 mice. The 44 mice were divided into three groups (Fig. 3a):

1) Treatment with i.v. injection of S. typhimurium A1-R $(n=15)$. 
S. typhimurium A1-R $\left(5 \times 10^{7} \mathrm{CFU}\right)$ in $100 \mu \mathrm{PBS}$ was injected i.v. once every seven days starting seven days post-implantation.

2) Treatment with i.p. injection of S. typhimurium A1-R $(\mathrm{n}=15)$.

S. typhimurium A1-R $\left(5 \times 10^{7} \mathrm{CFU}\right)$ in $100 \mu \mathrm{PBS}$ was injected i.p. once every seven days, starting seven days after cell injection.

3) No treatment group $(n=14)$.

The overall survival time of each group was determined. The body weight of all mice was measured at day $0,1,2,5,7,9,14$ in order to assess toxicity of $S$. typhimurium A1-R therapy.

\section{Tumor selectivity of $S$. typhimurium A1-R}

SKOV3-GFP $\left(5 \times 10^{6}\right.$ cells $)$ were injected i.p. in 10 nude mice. Fourteen days after the implantation, five mice were treated with i.v. injection of S. typhimurium A1-R $\left(5 \times 10^{7} \mathrm{CFU}\right)$ and another five mice were treated with i.p. injection of S. typhimurium A1-R $\left(5 \times 10^{7} \mathrm{CFU}\right)$. Ten nude mice without tumor were also treated with $S$. typhimurium A1-R i.v. or i.p., five mice each (Fig. 4a). Twenty-four hours after bacterial administration, blood, ascites, liver, spleen and tumor were harvested and seeded in LBAgar dishes. After 24-hour culture, S. typhimurium A1-R colony formation was assessed with fluorescence imaging (OV100, Olympus, Japan) (Fig. 4b, c).

\section{Statistical analysis}

Data comparisons between two groups were assessed using the Student's $\boldsymbol{t}$-test. When more than two groups were assessed, analysis of variance (ANOVA) was used. The Kaplan-Meier method was used for survival analysis. The log-rank test was used for statistical significance of the difference between the two groups. Differences were considered significant when $\mathrm{P}<0.05$. Data are expressed as mean \pm standard error (SE). Statistical analyses were performed with EZR (Saitama Medical Center, Jichi Medical University).

\section{CONFLICTS OF INTEREST}

$\mathrm{MZ}$ and $\mathrm{YZ}$ are employees of AntiCancer Inc. YM, SM, SY, FU, MY, YH, MT, MB, HM, HT and RMH are or were unsalaried associates of AntiCancer Inc. There are no other competing financial interests.

\section{Author's contributions}

YM, SM, MZ and RMH contributed to the conception and design. YM, SM, MZ, YZ, SY, FU, MY, $\mathrm{YH}, \mathrm{MT}, \mathrm{HM}, \mathrm{HT}, \mathrm{MB}$ and RMH did the analysis and interpretation. SM, YM, SY, FU, MY, YH and MT did the data collection. YM, SM, MZ and RMH wrote the manuscript. MZ, MB and RMH did the critical revision of the article. All authors read and approved the final manuscript.

\section{DEDICATION}

This paper is dedicated to the memory of A. R. Moossa, MD.

\section{REFERENCES}

1. Siegel R, Naishadham D, Jemal A. Cancer statistics. 2013. CA Cancer J Clin 2013;63:11-30.

2. Howlader N, Noone AM, Krapcho M, Garshell J, Neyman N, Altekruse SF, Kosary CL, Yu M, Ruhl J, Tatalovich Z, Cho H, Mariotto A, Lewis DR, Chen HS, Feuer EJ, Cronin KA, editors. SEER Cancer Statistics Review, 1975-2010, National Cancer Institute, Bethesda, MD, http://seer.cancer. gov/csr/1975_2010/, based on November 2012 SEER data submission, posted to the SEER web site, April 2013.

3. American Cancer Society. 2013. [http://www.cancer.org/].

4. Cannistra SA, Bast RC, Jr, Berek JS. Progress in the management of gynecologic cancer: Consensus summary statement. J Clin Oncol 2003;21:129s-32s.

5. William Coley. Available at: http://en.wikipedia.org/wiki/ William_Coley [last accessed 12 December 2013].

6. Hoffman RM. The preclinical discovery of bacterial therapy for the treatment of metastatic cancer with unique advantages. Expert Opin Drug Discov 2012;7:73-83.

7. Forbes NS. Engineering the perfect (bacterial) cancer therapy. Nat Rev Cancer 2010;10:785-94.

8. Yazawa K, Fujimori M, Nakamura T, Sasaki T, Amano J, Kano Y, Taniguchi S. Bifidobacterium longum as a delivery system for gene therapy of chemically induced rat mammary tumors. Breast Cancer Res Treat 2001;66:16570.

9. Dang LH, Bettegowda C, Huso DL, Kinzler KW, Vogelstein B. Combination bacteriolytic therapy for the treatment of experimental tumors. Proc Natl Acad Sci USA 2001;98:15155-60.

10. Roberts NJ, Zhang L, Janku F, Collins A, Bai RY, Staedtke V, Rusk AW, Tung D, Miller M, Roix J, Khanna KV, Murthy R, Benjamin RS, Helgason T, Szvalb AD, Bird JE, Roy-Chowdhuri S, Zhang HH, Qiao Y, Karim B, McDaniel J, Elpiner A, Sahora A, Lachowicz J, Phillips B, Turner A, Klein MK, Post G, Diaz LA Jr, Riggins GJ, Papadopoulos N, Kinzler KW, Vogelstein B, Bettegowda C, Huso DL, Varterasian M, Saha S, Zhou S. Intratumoral injection of Clostridium novyi-NT spores induces antitumor responses. Sci Transl Med 2014;6:249ra111.

11. Pawelek JM, Low KB, Bermudes D. Bacteria as tumourtargeting vectors. Lancet Oncol 2003;4:548-56. 
12. Toso JF, Gill VJ, Hwu P, Marincola FM, Restifo NP, Schwartzentruber DJ, Sherry RM, Topalian SL, Yang JC, Stock F, Freezer LJ, Morton KE, Seipp C, Haworth L, Mavroukakis S, White D, MacDonald S, Mao J, Sznol M, Rosenberg SA. Phase I study of the intravenous administration of attenuated Salmonella typhimurium to patients with metastatic melanoma. J Clin Oncol 2002;20:142-52.

13. Zhang Y, Zhang N, Hoffman RM, Zhao M. Comparision of the selective targeting efficacy of $S$. typhimurium A1-R and VNP20009 on the lewis lung carcinoma in nude mice. Oncotarget 2015:Epub ahead of print.

14. Zhao M, Yang Y, Li XM, Jiang P, Baranov E, Li S, Xu M, Penman S, Hoffman RM. Tumor-targeting bacterial therapy with amino acid auxotrophs of GFP-expressing Salmonella typhimurium. Proc Natl Acad Sci USA 2005;102:755-60.

15. Zhao M, Yang M, Ma H, Li X, Tan X, Li S, Yang Z, Hoffman RM. Targeted therapy with a Salmonella typhimurium leucine-arginine auxotroph cures orthotopic human breast tumors in nude mice. Cancer Res 2006;66:7647-52.

16. Zhao M, Geller J, Ma H, Yang M, Penman S, Hoffman RM. Monotherapy with a tumor-targeting mutant of Salmonella typhimurium cures orthotopic metastatic mouse models of human prostate cancer. Proc Natl Acad Sci USA 2007; 104:10170-4.

17. Hayashi K, Zhao M, Yamauchi K, Yamamoto N, Tsuchiya H, Tomita K, Kishimoto H, Bouvet M, Hoffman RM . Systemic targeting of primary bone tumor and lung metastasis of high-grade osteosarcoma in nude mice with a tumor-selective strain of Salmonella typhimurium. Cell Cycle 2009;8:870-5.

18. Nagakura C, Hayashi K, Zhao M, Yamauchi K, Yamamoto N, Tsuchiya H, Tomita K, Bouvet M, Hoffman RM. Efficacy of a genetically-modified Salmonella typhimuriumin an orthotopic human pancreatic cancer in nude mice. Anticancer Res 2009;29:1873-8.

19. Kimura H, Zhang L, Zhao M, Hayashi K, Tsuchiya H, Tomita K, Bouvet M, Wessels J, Hoffman RM. Targeted therapy of spinal cord glioma with a genetically-modified Salmonella typhimurium. Cell Prolif 2010;43:41-8.

20. Yam C, Zhao M, Hayashi K, Ma H, Kishimoto H, McElroy M, Bouvet M, Hoffman RM . Monotherapy with a tumortargeting mutant of Salmonella typhimurium controls liver metastasis in a mouse model of pancreatic cancer. J Surg Res 2010;164:248-55.

21. Momiyama M, Zhao M, Kimura H, Tran B, Chishima T, Bouvet M, Endo I, Hoffman RM. 2012. Inhibition and eradication of human glioma with tumor targeting Salmonella typhimurium in an orthotopic nude-mouse model. Cell Cycle 2012;11:628-32.

22. Uchugonova A, Zhao M, Zhang Y, Weinigel M, König K, Hoffman RM. Cancer-cell killing by engineered Salmonella imaged by multiphoton tomography in live mice. Anticancer Res 2012;32:4331-38.
23. Leschner S, Westphal K, Dietrich N, Viegas N, Jablonska J, Lyszkiewicz M, Lienenklaus S, Falk W, Gekara N, Loessner H, Weiss S. Tumor invasion of Salmonella enterica serovar Typhimurium is accompanied by strong hemorrhage promoted by TNFa. PLoS ONE 2009;4:e6692.

24. Liu F, Zhang L, Hoffman RM, Zhao M. Vessel destruction by tumor targeting Salmonella typhimurium A1-R is enhanced by high tumor vascularity. Cell Cycle 2010;9:4518-24.

25. Hiroshima Y, Zhao M, Zhang Y, Maawy A, Hassanein MK, Uehara F, Miwa S, Yano S, Momiyama M, Suetsugu A, Chishima T, Tanaka K, Bouvet M, Endo I, Hoffman RM. Comparison of efficacy of Salmonella typhimurium A1-R and chemotherapy on stem-like and non-stem human pancreatic cancer cells. Cell Cycle 2013;12:2774-80.

26. Hiroshima Y, Zhao M, Maawy A, Zhang Y, Katz MH, Fleming JB, Uehara F, Miwa S, Yano S, Momiyama M, Suetsugu A, Chishima T, Tanaka K, Bouvet M, Endo I, Hoffman RM. Efficacy of Salmonella typhimurium A1-R versus chemotherapy on a pancreatic cancer patientderived orthotopic xenograft (PDOX). J Cell Biochem 2014;115:1254-61.

27. Matsumoto Y, Miwa S, Zhang Y, Hiroshima Y, Yano S, Uehara F, Yamamoto M, Toneri M, Bouvet M, Matsubara H, Hoffman RM, Zhao M. Efficacy of tumor-targeting Salmonella typhimurium A1-R on nude mouse models of metastatic and disseminated human ovarian Cancer, J. Cell. Biochem 2014;115:1996-2003.

28. Blagosklonny MV. How cancer could be cured by 2015 . Cell Cycle 2005;4:269-78.

29. Blagosklonny MV. Tissue-selective therapy of cancer. Br J Cancer 2003;89:1147-51.

30. Blagosklonny MV. Matching targets for selective cancer therapy. Drug Discov Today 2003;8:1104-7.

31. Blagosklonny MV. "Targeting the absence" and therapeutic engineering for cancer therapy.Cell Cycle 2008;7:1307-12.

32. Blagosklonny MV. Teratogens as anti-cancer drugs. Cell Cycle 2005;4:1518-21.

33. Blagosklonny MV. Treatment with inhibitors of caspases, that are substrates of drug transporters, selectively permits chemotherapy-induced apoptosis in multidrug-resistant cells but protects normal cells. Leukemia 2001;15:936-41.

34. Blagosklonny MV. Target for cancer therapy: proliferating cells or stem cells. Leukemia 2006;20:385-91.

35. Blagosklonny MV. Cancer stem cell and cancer stemloids: from biology to therapy. Cancer Biol Ther 2007;6:1684-90.

36. Buick RN, Pullano R, Trent JM. Comparative properties of five human ovarian adenocarcinoma cell lines. Cancer Res 1985;45:3668-76.

37. Yamauchi $\mathrm{K}$, Yang $\mathrm{M}$, Jiang $\mathrm{P}, \mathrm{Xu} \mathrm{M}$, Yamamoto $\mathrm{N}$, Tsuchiya H, Tomita K, Moossa AR, Bouvet M, Hoffman RM. Development of real-time subcellular dynamic multicolor imaging of cancer-cell trafficking in live mice with a variable-magnification whole-mouse imaging 
system. Cancer Res 2006;66:4208-14. 